\title{
Hybrid NOTES transgastric cholecystectomy with reliable gastric closure: an animal survival study
}

\author{
Rogier P. Voermans • Mark I. van Berge Henegouwen • \\ Willem A. Bemelman • Paul Fockens
}

Received: 15 October 2009/ Accepted: 27 February 2010/Published online: 19 August 2010

(C) The Author(s) 2010. This article is published with open access at Springerlink.com

\begin{abstract}
Background Secure transluminal closure remains the most fundamental barrier to safe translation of transgastric natural orifice transluminal endoscopic surgery (NOTES) procedures to humans. Obtaining optimal critical view of safety (CVS) is a prerequisite to performing cholecystectomy avoiding common bile duct injury.

Objectives (1) To evaluate feasibility and safety of hybrid transgastric NOTES cholecystectomy. (2) To evaluate feasibility and reliability of gastrotomy closure using a novel Over-The-Scope-Clip (OTSC; Ovesco) in survival porcine experiments.

Methods Laparoscopic access to the abdominal cavity was obtained by two 2-mm and one umbilical optical trocar(s). Gastric access was created by balloon dilatation of a needle knife puncture up to $18 \mathrm{~mm}$. Exposure of CVS was obtained and evaluated by aid of a 2-mm device. Subsequently the cystic duct and artery were clipped endoscopically. After laparoscopic dissection the specimen was extracted via the stomach. The gastrotomy was closed endoscopically using the OTSC. Necropsy was performed
\end{abstract}

Electronic supplementary material The online version of this article (doi:10.1007/s00464-010-1242-4) contains supplementary material, which is available to authorized users.

R. P. Voermans · P. Fockens $(\bowtie)$

Department of Gastroenterology and Hepatology, Academic

Medical Center, University of Amsterdam, P.O. Box 22700,

1100 DE Amsterdam, The Netherlands

e-mail: p.fockens@amc.nl

R. P. Voermans - M. I. van Berge Henegouwen .

W. A. Bemelman

Department of Surgery, Academic Medical Center,

University of Amsterdam, Amsterdam, The Netherlands after 10 days with inspection of gastrotomy and peritoneal cavity for complications. Experiments were planned in 3 acute and 16 survival pigs. Main outcome parameters were documented exposure of CVS, successful cholecystectomy and closure, uncomplicated survival and histology-confirmed full-thickness closure.

Results In all 16 survival experiments CVS was obtained satisfactorily and hybrid cholecystectomy was successfully performed $[100 \% ; 95 \%$ confidence interval (CI): 81-100\%]. Transgastric closure was endoscopically successful in all experiments in mean time of $7 \mathrm{~min}$ [standard deviation (SD) $3 \mathrm{~min}$ ]. At necropsy 10 days after surgery there were no signs of (infectious) complications. Histology confirmed full-thickness healing with $100 \%$ success (95\% CI: 81-100\%).

Conclusion Hybrid transgastric NOTES cholecystectomy is feasible, safe and results in optimal CVS. Use of OTSC for gastrotomy closure is feasible, reliable and results in histology-proven full-thickness closure in survival porcine experiments.

Keywords Therapeutic/palliation, endoscopy · G-I, endoscopy · Surgical, technical · Instruments, technical · Cholecystectomy · Digestive · Gastrointestinal perforations $\cdot$ Endoscopic closure $\cdot$ Critical view of safety

In recent years, the borders between surgery and gastroenterology have become less clear through the development of natural orifice transluminal endoscopic surgery (NOTES). NOTES is being developed with the aim of performing even less invasive surgery than laparoscopic surgery. In its ultimate form it will avoid abdominal incisions for trocar openings as well as extraction incisions necessary for specimen removal. Consequently, incision- 
related complications, such as surgical-site infection and hernia, are avoided and patients potentially recover faster with less postoperative stress and pain.

Cholecystectomy is the most common elective surgical procedure and is one of the key procedures which is evaluated to identify its potential to become a NOTES procedure. NOTES cholecystectomy has been shown to be feasible in animal models [1-7] and human case reports [813]. The vast majority of these human case studies have used the transvaginal route. This approach does not seem to be the ultimate solution as it could possibly cause dyspareunia and adhesion-related infertility and can only be used in $50 \%$ of the population [14-16].

There are at least two major technical challenges which need to be surmounted before transgastric NOTES cholecystectomy can be safely introduced in human clinical trials. First of all, endoscopic closure of the gastrotomy after the transgastric procedure needs to be safe and reliable. Considering the safety of laparoscopy, even a $1 \%$ leak rate from the gastrotomy closure site would not be acceptable. Any appreciable increase in patient morbidity due to post-NOTES leakage from the gastrointestinal tract would erase all possible patient advantages compared with conventional laparoscopy. A wide variety of NOTES closure modalities have been described in ex vivo experiments and (non-)survival animal studies [3, 4, 17-24]. We have reported an ex vivo experimental set-up in which the majority of current NOTES closure modalities have been evaluated and compared with surgical hand suture [23, 25]. In this model we also tested a new device, called the OverThe-Scope-Clip (OTSC; Ovesco Endoscopy, Tuebingen, Germany). This resulted in adequate ex vivo closure in a relatively short amount of time [25]. The second major challenge concerns adequate exposure of the operative field. Exposure of the critical view of safety (CVS) before clipping the artery and duct has been shown to reduce bile duct injuries [26, 27]. It is therefore essential that CVS be obtained in any model investigating NOTES cholecystectomy [27]. Using current endoscopic technology, triangulation of instruments to achieve this CVS is not possible as endoscopic instruments can only move in and out of the endoscopic working channels in one dimension. Therefore, safe transgastric NOTES cholecystectomy cannot be ensured using endoscopic equipment only. A hybrid transgastric procedure using additional 2-mm laparoscopic instruments might overcome these problems, with the advantage of avoiding an abdominal incision because the gallbladder can be removed through the stomach. By using 2-mm instruments the risk of hernia formation is avoided and no remnant scars will be visible. Furthermore, safety can be ensured by laparoscopic inspection of endoscopic closure. This minimally invasive procedure may lead to acceptable operating times, less postoperative pain and faster recovery than after standard laparoscopic cholecystectomy and serve as a safe and essential bridge to potential pure NOTES procedures.

The above-mentioned challenges led to the following aims of the present study: (1) to evaluate feasibility and safety of hybrid transgastric NOTES cholecystectomy using a double-channel gastroscope and 2-mm laparoscopic instruments, and (2) to evaluate feasibility, safety and reliability of gastrotomy closure using the OTSC in survival porcine experiments.

\section{Methods}

Animals and preparation

Sixteen survival experiments were performed on $50-55-\mathrm{kg}$ female pigs. Institutional review board (IRB) approval was obtained from the local animal ethics committee, and animals were housed at the animal research facility at Academic Medical Hospital, University of Amsterdam, The Netherlands.

The animals were prepared and anaesthetised as previously described [28]. All endoscopes were disinfected with glutaraldehyde in an Olympus Thermo-disinfector (ETD2; Olympus Medical Systems Europe, Hamburg, Germany) and air-dried for high-level disinfection before each procedure. All used accessories were either sterile from manufacturer or were gas-sterilized before use. At the start of the procedure the stomach was lavaged endoscopically (GIF XTQ160; Olympus) with $500 \mathrm{ml}$ suspension of $1,000 \mathrm{mg}$ ceftriaxone in sterile $0.9 \% \mathrm{NaCl}$. After $5 \mathrm{~min}$, the suspension was aspirated using endoscopic suction. All animals received 1,000 ceftriaxone $\mathrm{mg}$ and $10 \mathrm{mg} / \mathrm{kg}$ metronidazole intravenous $30 \mathrm{~min}$ before the start of the procedure.

\section{Peritoneal access and trocar introduction}

All experiments were performed with the animal in supine position by two experienced surgeons (M.v.B.H. and W.B.) and one experienced therapeutic endoscopist (P.F.). Prior to peritoneal access, $\mathrm{CO}_{2}$ pneumoperitoneum $(10 \mathrm{mmHg})$ was induced using a Veress needle, introduced just below the umbilicus. Access to the abdominal cavity was obtained by two $2-\mathrm{mm}$ trocars (left and right upper abdomen) and one 2- or 5-mm trocar (optic port; umbilicus). A 2-mm $0^{\circ}$ needlescope (Storz Endoskope, Tuttlingen, Germany) or a 5 -mm $30^{\circ}$ videoscope (Endo Eye, Olympus) was introduced through the umbilical trocar. In case the 2-mm videoscope was not available, a 5-mm device was used instead. The 5-mm port was only used for visualisation, and the procedures were not different apart from the size of the videoscope. 
Simultaneously, a sterile overtube and a second disinfected double-channel endoscope (Olympus GIF 2T160 or Storz 13806 PKS) was introduced into the stomach. Endoscopic access to the peritoneal cavity was performed under laparoscopic control. The anterior gastric wall was located endoscopically by internal indentation from abdominal palpation and/or installation of water. The gastrotomy was preferentially created at the anterior wall of the stomach, or if not possible at an acceptable spot on the posterior wall near the greater curvature. Access was created by needle knife (HPC3; Cook Endoscopy, Winston-Salem, NC, USA) puncture followed by introduction of a 0.035-inch guidewire (Jagwire; Boston Scientific, Natick, MA, USA) and dilatation with an 18-mm dilation balloon (CRE, Boston) after which the endoscope was introduced into the peritoneal cavity.

\section{Cholecystectomy}

After introduction of the endoscope and distal part of the overtube into the peritoneal cavity the fundus of the gallbladder was retracted endoscopically to expose the gallbladder bed to the laparoscopist (Fig. 1A). The neck of the gallbladder was dissected from the liver bed using a 2-mm electrocautery hook (Storz), and the triangle of Calot was exposed and documented laparoscopically. After obtaining
CVS laparoscopically (Fig. 1B), the cystic duct and artery were clipped simultaneous using endoscopic Resolution (Boston) or Quick Clips (Olympus). The gallbladder was laparoscopically dissected from the liver bed using endoscopic assistance. After dissection, the specimen was grasped with an endoscopic snare. To facilitate transgastric removal, the bile was evacuated out of the gallbladder using a 19-G EUS needle (Cook) through the second channel of the therapeutic gastroscope. After evacuation of the bile the gallbladder was retracted via the stomach and oesophagus and finally removed via the mouth.

\section{Gastrotomy closure}

After removal of the specimen, the overtube was removed and the OTSC-cap (Ovesco) was mounted on the tip of the endoscope. The endoscope, with the OTSC installed on the applicator cap (Fig. 2A), was introduced into the stomach. To approximate both sites of the gastrotomy before closure, a twin grasper (Ovesco, Fig. 2B) was deployed through the working channel. The twin grasper has one fixed middle branch and two independently movable lateral branches, which enable grasping of the serosal layer of both incision edges separately. Consequently, the tissue was approximated and gently pulled into the OTSC application cap while applying continuous suction through the endoscope
Fig. 1 Laparoscopic images showing hybrid

cholecystectomy: A fundus of the gallbladder being retracted endoscopically to expose the gallbladder bed; B critical view of safety. In the lower half the endoscopic clip can be seen
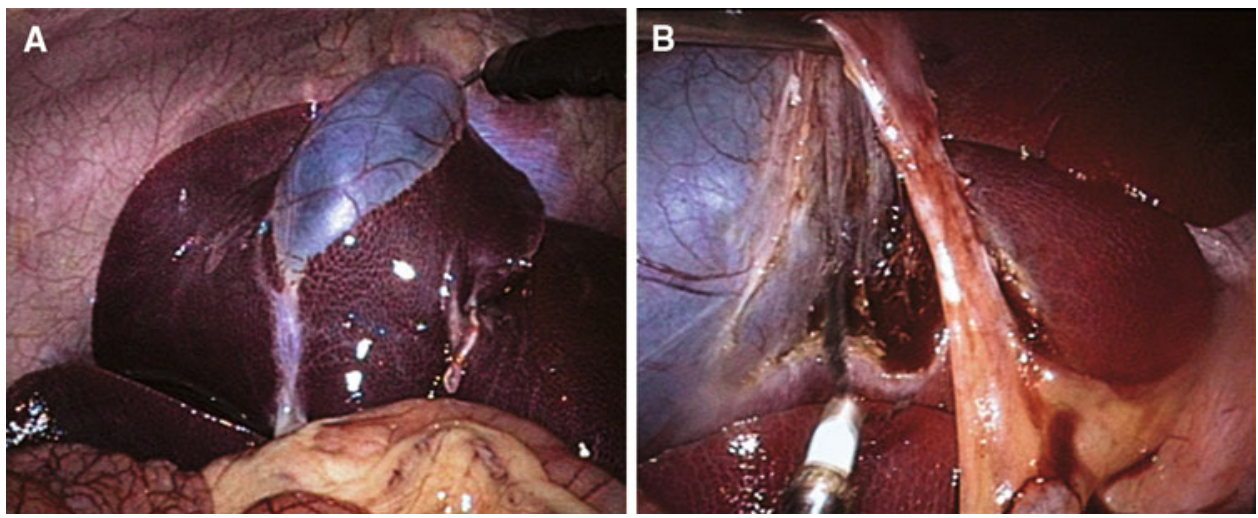

Fig. 2 Images showing the Over-The-Scope-Clip (OTSC) system: A laparoscopic image showing the OTSC cap mounted on the tip of endoscope; B drawing depicting the twin grasper with one fixed middle branch and two independently mobile lateral branches

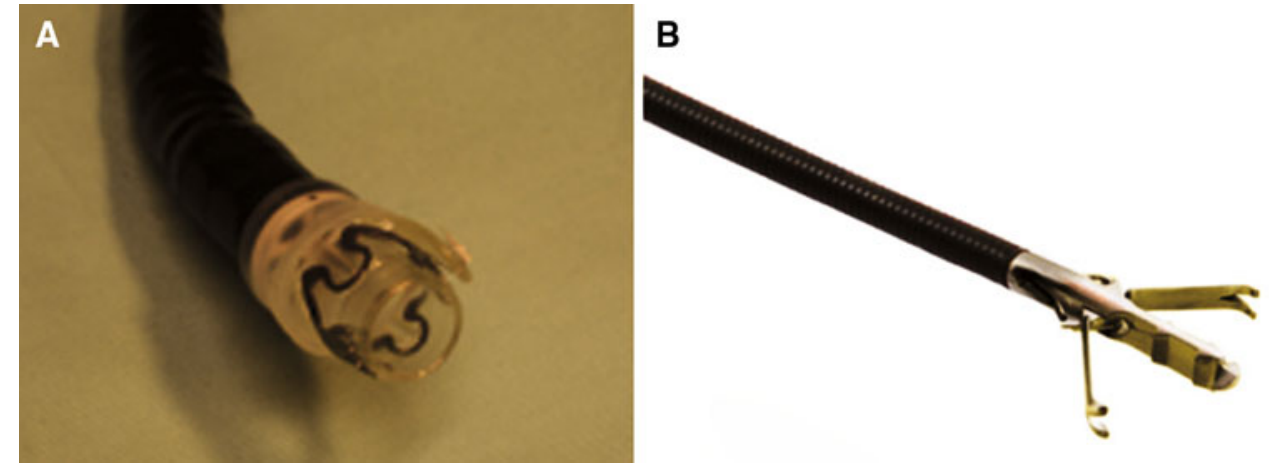


as well. The OTSC was then released by pulling on a wire that is led through the working channel of the endoscope (similar to endoscopic band ligation).

Gastrotomy closure was checked for airtightness by insufflating the stomach endoscopically and simultaneously spraying a water film laparoscopically onto the closed gastrotomy. In case of leakage, air bubbles could be visualized and the closure could be optimized endoscopically using another OTSC or additional endoclips. If the gastrotomy continued to leak after optimal endoscopic closure, the protocol obligated the laparoscopist to oversew the gastrotomy using 2-mm instruments.

Follow-up

The pigs were given a regular diet directly after recovery from general anaesthesia (about $4 \mathrm{~h}$ after procedure). Pigs were extensively monitored on a daily basis for signs of peritonitis or other distress by an experienced biotechnician. All pigs received intravenous antibiotics for 3 days: $10 \mathrm{mg} / \mathrm{kg}$ metronidazole divided into three doses and $1,000 \mathrm{mg} /$ day ceftriaxone.

After 10 days the animals were euthanized. Necropsy consisted of examination of the peritoneal cavity to identify signs of organ injury, adhesions or infectious complications. The closed access site was inspected in detail for macroscopic full-thickness healing, adhesions or abscesses. The closed gastrotomy was excised and sent for histological examination to evaluate full-thickness healing. If there was suspicion of infectious complication at another site, it was excised and sent for histology as well.

\section{Statistics and outcome parameters}

Primary outcome parameters were: uncomplicated followup during 10 days survival (defined as absence of clinical signs of peritonitis), histology-confirmed full-thickness closure after 10 days survival and adequate exposure of CVS.

Secondary outcomes were procedural time (from introduction of the sterile endoscope until adequate closure), immediate successful closure, closure time (from introduction of the OTSC until adequate closure), successful cholecystectomy, bile leakage at necropsy, number of adhesions, number of (micro-)abscesses and number of (peri)operative complications. Successful cholecystectomy was defined as absence of the need to convert to larger laparoscopic instruments or open procedure. Immediate successful closure was defined as absence of air bubbles after final endoscopic closure.

Experiments were first planned in three non-survival porcine experiments to optimize the procedure. Sample size for survival experiments was based on the fact that the lower end of the $95 \%$ confidence interval (CI) of successful closure must be at least above $80 \%$ to draw conclusions. With the assumption of a success rate of $100 \%$ for primary outcome parameters, 16 survival pigs needed to be included to finally achieve a lower end of the $95 \%$ confidence interval (CI) of at least $80 \%$.

All calculations were carried out using the Statistical Package for Social Sciences 12.0.1 software package (SPSS Inc., Chicago, IL, USA) for Windows. Quantitative data are expressed as median plus range or as mean plus standard deviation (SD) when appropriate.

\section{Results}

Results are summarized in Table 1. Peritoneal access was successfully achieved in all 16 survival animals. In six experiments access was created at the posterior wall of the stomach instead of at the anterior wall. In one survival pig there was a small laceration of the liver caused during needle knife insertion, which was managed conservatively. In the majority of the pigs (13/16) it was not possible to introduce the overtube through the gastrotomy into the peritoneal cavity (not enough length of overtube). In all experiments CVS was obtained and documented satisfactorily (Fig. 1B). In all pigs the cystic duct and artery were successfully clipped endoscopically using a median of 3 clips (range 3-4). Hybrid cholecystectomy was successful in all 16 animals (100\%; 95\% CI: 85-100\%). Perioperative minor bleeding occurred in three cases: in two pigs it was managed endoscopically using endoclips (on the cystic

Table 1 Summary of main outcome parameters of survival experiments $(n=16)$

\begin{tabular}{lll}
\hline Outcome parameter & Outcome & $95 \%$ CI or SD \\
\hline Cholecystectomy & & \\
$\quad$ Adequate exposure of CVS & $16 / 16(100 \%)$ & $81-100 \%$ \\
$\quad \begin{array}{l}\text { Successful cholecystectomy } \\
\text { Endoscopic closure }\end{array}$ & $16 / 16(100 \%)$ & $81-100 \%$ \\
$\quad$ Immediate successful & $16 / 16(100 \%)$ & $81-100 \%$ \\
$\quad$ endoscopic closure & $16 / 16(100 \%)$ & $81-100 \%$ \\
$\quad$ Histology-proven & & \\
$\quad$ full-thickness closure & & $1-28 \%$ \\
$\begin{array}{l}\text { Complications } \\
\text { Access-related complications }\end{array}$ & $1 / 16(6 \%)$ & $4-36 \%$ \\
$\quad$ Minor bleeding during & $2 / 16(13 \%)$ & \\
$\quad$ cholecystectomy & $16 / 16(100 \%)$ & $81-100 \%$ \\
Uncomplicated 10-day follow-up & 7 min & SD 3 min \\
Closure time & 73 min & SD 23 min \\
Total procedural time &
\end{tabular}

CI confidence interval, $S D$ standard deviation, $C V S$ critical view of safety 
artery and liver bed), and in one case the bleeding (from the liver bed) was laparoscopically oversewn using 2-mm instruments. In two experiments the gallbladder was perforated during laparoscopic dissection from the liver bed. Retraction of the gallbladder through the gastrotomy and oesophagus was successful in all animals. Mean total procedural time was $73 \mathrm{~min}$ (SD $23 \mathrm{~min}$ ).

Endoscopic gastrotomy closure was macroscopically successful in all 16 survival animals using one OTSC in all cases (Fig. 3A, B). In one case, leakage of air bubbles from the lateral site of the gastrotomy was laparoscopically visualized during endoscopic insufflation of the stomach. The leakage was successfully closed endoscopically with one Resolution clip. In none of the cases was it necessary to oversew the gastrotomy laparoscopically. Mean closure time was 7 min (SD $3 \mathrm{~min}$ ).

All survival animals had uncomplicated postoperative recovery and resumed oral intake within $4 \mathrm{~h}$ postoperatively. All 16 pigs thrived during follow-up, gaining mean weight of $6.9 \mathrm{~kg}$ (SD $1 \mathrm{~kg}$ ) in 10 days. At necropsy after 10 days survival there were no macroscopic signs of intraperitoneal infection or bile leakage in the peritoneal cavity. In all 16 cases the clips were still present on the cystic duct and artery. The gastrotomy was macroscopically full-thickness closed in all cases (Fig. 4A, B). In 10/ $16(63 \%)$ the OTSC was still present at the closure site and was not overgrown by mucosa. In one case the OTSC was found loose in the stomach, and in the remaining five animals the OTSC was not detected at necropsy. Histology of the excised closed gastrotomy confirmed full-thickness, serosa-to-serosa healing in $100 \%$ of cases $(95 \%$ CI: $81-100 \%)$ and showed no signs of local infection or abscesses. In 8/16 (50\%), adhesions from the gastrotomy to omentum were found. In 6/8 (75\%) cases with omentum-
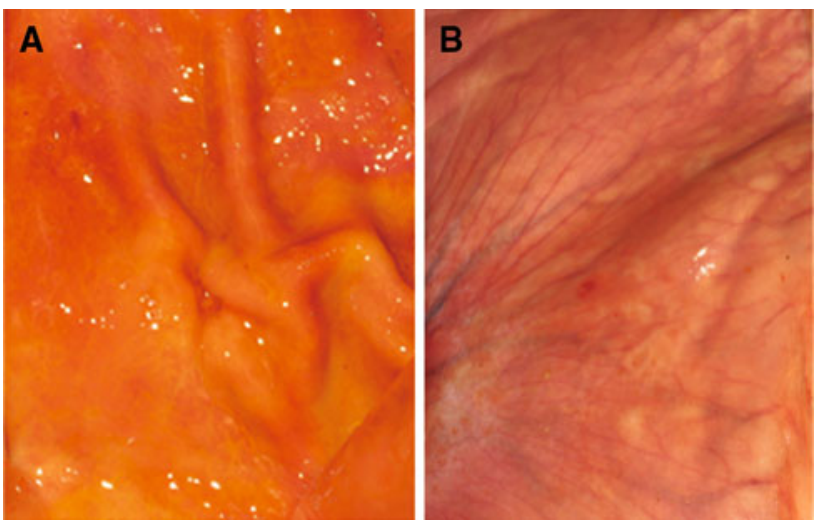

Fig. 4 Image showing mucosal (A) and serosal (B) site of the gastrotomy at necropsy after 10 days survival

related adhesions the gastrotomy was created at the posterior wall of the stomach.

\section{Discussion}

Transgastric cholecystectomy might be one of the key procedures in the application of NOTES technology. Before broad application of NOTES cholecystectomy, the procedure must be completely safe with respect to closure of the access site. In addition, proper exposure of CVS must be reached before clipping the cystic duct and artery, and overall procedural time must be acceptable. The present, animal study demonstrated that hybrid NOTES transgastric cholecystectomy with gastric closure using OTSC guaranteed proper exposure of CVS and safe gastric closure with acceptable procedural time.

Using this hybrid technique, essential CVS was adequately visualised in all cases. Establishing CVS before

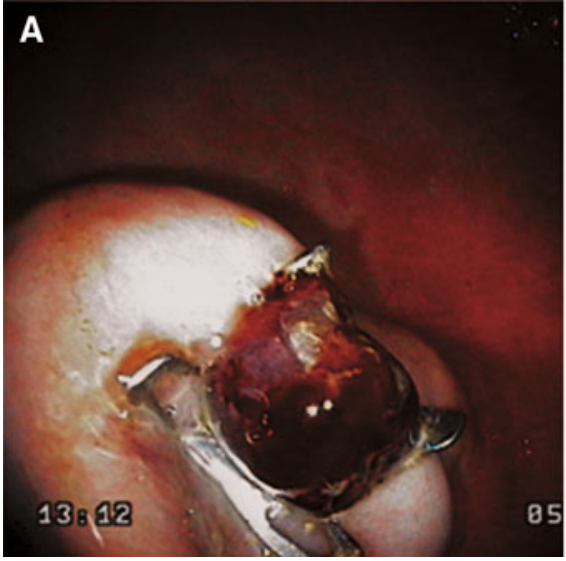

Fig. 3 Images showing endoscopic gastrotomy closure: A endoscopic image showing macroscopically adequately closed gastrotomy using the Over-The-Scope-Clip; B laparoscopic image showing leak testing of the gastrotomy after closure by insufflating the stomach

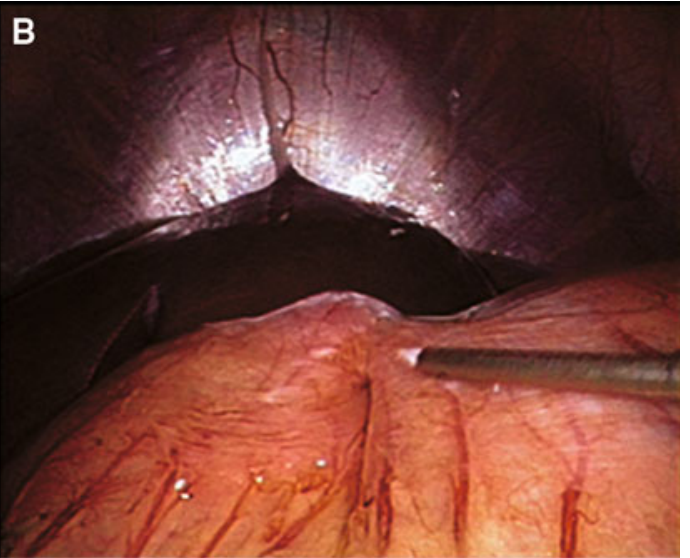

endoscopically and simultaneously spraying a water film laparoscopically. No leakage of air bubbles could be visualized through the inverted closed gastrotomy. Note the inverted, serosa-to-serosa closure 
ligation and division of the artery and duct has been shown to reduce bile duct injuries associated with laparoscopic cholecystectomy [26, 27]. Lessons could be learned from the introduction of laparoscopic cholecystectomy two decades ago. Laparoscopic cholecystectomy was introduced too fast, driven by the media, patient demand, industry and physician competition. Initially, this led to a relative high rate of bile duct injuries and consequently considerable patient disability [26, 29]. If NOTES cholecystectomy is to become the even less invasive alternative to laparoscopic cholecystectomy it should be introduced safely and in a controlled fashion.

However, using current endoscopic technology with working channels oriented parallel to optics, it is impossible to achieve essential CVS. By using mini-instruments ( $2 \mathrm{~mm}$ ) we attempted to be as minimally invasive as currently possible in combination with maintenance of the ability to triangulate, which is necessary to overview the triangle of Calot adequately. Therefore CVS should be obtained in each case. The current report is, to the best of our knowledge, the first (hybrid) NOTES cholecystectomy report in which CVS was obtained in all cases. Until the availability of dedicated NOTES endoscopes, we believe that a hybrid technique is the safest and only responsible way to introduce NOTES into human clinical trials. Furthermore, by translating laparoscopic-assisted NOTES cholecystectomy to humans, transgastric access and endoscopic closure could be evaluated and developed in a safe and controlled way as well, forming an excellent bridge to pure NOTES procedures.

Secure transluminal closure remains the most fundamental barrier to safe introduction of transgastric NOTES procedures into human clinical trials. This relatively large, survival animal study showed feasibility, safety and reliability of gastrotomy closure using the OTSC. Although feasibility of a variety of gastric closure modalities has been described in survival animal studies [4, 20, 24, 30, 31 ], this is, to the best of our knowledge, the first survival animal study with $100 \%$ success in combination with a 95\% CI narrow enough to draw conclusions.

The optimal introduction of an experimental technique can be divided in three phases: first an ex vivo evaluation and comparison, secondly an in vivo animal evaluation, and finally, if these two phases are successfully completed, a human pilot study can be performed. We selected the OTSC for in vivo survival evaluation after first conducting an ex vivo comparison study $[23,25]$. In this ex vivo study a considerable part of these closure techniques appeared to be comparable with gold-standard values and the endoscopic stapler, flexible endostitch and OTSC resulted in, respectively, the strongest closures [23, 25]. However, the flexible endostitch and stapler are (still) relatively large in diameter and are limited in their manoeuvrability. Therefore, these modalities are challenging to apply in vivo in the confined space of the stomach. Additionally, the lack of adequate insufflation of the stomach due to air leakage through the gastrotomy impairs manoeuvring these closure modalities even more. In contrast, the OTSC closure technique resembles that of rubber band ligation which is a well-known and relative easy procedure for therapeutic endoscopists. Ease of the procedure was confirmed by the short mean closure time of $7 \mathrm{~min}$. This is in contrast with a number of other closure modalities reported in literature (mean closure time 15-26 min) [4, 24, 30, 32, 33]. Feasibility of gastrotomy closure using the OTSC has already been proven in non-survival porcine experiments and a small survival animal study [19, 24, 34]. Although the only survival animal study was a comparative trial, the different groups consisted of only five animals each. Consequently, the $95 \%$ CI was $57-100 \%$ (in case of $100 \%$ success) and it is hard to draw real conclusions [34]. Essential, adequately powered, survival animal studies have, to the best of our knowledge, not yet been reported.

Standard endoscopic clips were used for ligation of the cystic duct and artery. These clips are, however, not designed to clip thin structures such as pig cystic duct and artery, but need more tissue to stay in position. Therefore both structures were clipped simultaneously in these animal experiments. Flexible, through-the-scope instruments that deliver laparoscopic clips are currently being developed and should overcome this issue [35]. Besides clipping, all principles of state-of-the-art cholecystectomy were strictly respected and could therefore be used to translate to a human setting in the future.

Access to the peritoneal cavity was obtained via the stomach. The stomach seems to be the preferred route compared with the colon and vagina because of contamination risk with colonic access and problems such as lower pelvic scarring which can cause dyspareunia and infertility with vaginal access [14-16, 36]. Moreover, the transvaginal approach excludes half of the population. However, a problem of the transgastric approach is the necessity to work in retroflexion, which reduces endoscope stability [37]. Due to reduced stability and the relatively short bending section of current endoscopes, reaching the gallbladder for intervention can be challenging with current endoscopic technology. During our experiments, access to the gallbladder appeared to be facilitated by: (1) creation of the access port near the antrum of the stomach and (2) reducing intra-abdominal $\mathrm{CO}_{2}$ pressure. Reduction of intraabdominal pressure reduced the distance from the entry port of the endoscope to the gallbladder and improved endoscopic access to this region. In contrast to laparoscopy, visualisation remained adequate during pressure reduction, probably because the entrance of the instruments into the peritoneal cavity via the transgastric approach is parallel to the abdominal wall. 
Besides visualisation, reduction of $\mathrm{CO}_{2}$ pressure could also be of benefit for postoperative outcome, since most postoperative laparoscopic stress is related to $\mathrm{CO}_{2}$ pressure $[38,39]$. In combination with avoidance of abdominal incisions, this approach may lead to reduction of postoperative pain and stress. The greatest benefits of the NOTES approach may be achieved in morbidly obese patients, since these patients have relatively high complication rates of abdominal incisions, such as wound infection and hernia formation, and are challenging to operate with standard laparoscopic instruments [40, 41]. However, besides the absence of abdominals scars, the benefits of the NOTES approach still have to be proven in clinical trials.

A transgastric approach brings additional risk as well. To reach the peritoneal cavity a hole has to be made in a healthy stomach. This may lead to bleeding or leakage of gastric contents into the peritoneal cavity during the procedure, and there is a risk of postprocedural leakage in case the gastrotomy is not closed reliably. We tried to prevent infectious complications of leakage as much as possible by preoperatively rinsing the stomach with an antibiotic solution and by the introduction of a sterile overtube through the gastrotomy. However, in the majority of cases, introduction of the sterile overtube was not successful because the overtube was too short for our relatively large pigs $(>50 \mathrm{~kg})$. Despite the issues with the overtube we did not encounter any infectious complications in our survival experiments. Furthermore, at necropsy there were no signs of leakage of gastric contents through the closed gastrotomies. The first human NOTES case series and human studies concerning bacterial contamination after surgical gastrojejunostomies also indicate that a temporarily open gastrotomy during intra-abdominal procedures does not lead to peritoneal infection $[42,43]$.

A few limitations of the animal model need to be mentioned. A randomized comparison with laparoscopic closure may have strengthened our conclusions. However, anticipating a success rate of almost $100 \%$ for relative easy laparoscopic closure, we would have had to include over 40 animals per group to show non-inferiority. Recognizing the need to balance cost with efficiency and to minimize the animals needed as much as possible, a cohort study seemed to be appropriate for this experimental study.

Performing cholecystectomy on a patient with symptomatic gallbladder stones is a different situation from operating on a pig with a non-inflamed gallbladder that does not contain stones. Especially removal of the gallbladder through the gastrostomy and oesophagus may produce difficulties in case of a gallbladder that is inflamed or filled with stones. Secondly, the pig has a relative long cystic duct, which could have influenced the procedure. To mimic the human situation as much as possible in the model used, we ensured preparation of not only the proximal part of the cystic duct but also the gallbladder neck from the liver bed (Video 1). Finally, the gastric anatomy of the pig is slightly different from the human stomach. For example, the porcine stomach tends to rotate ventrally during insufflation of the stomach; consequently, it was sometimes challenging to create the gastrotomy at the favourable anterior site of the stomach. In six experiments the gastrotomy was indeed created at the posterior wall. In humans the latter difficulty will probably not occur.

In conclusion, hybrid transgastric NOTES cholecystectomy is feasible, safe and fast and results in optimal CVS in survival porcine experiments. Secondly, use of OTSC for gastrotomy closure is feasible and reliable and results in histology-proven full-thickness closure. This procedure seems to be a safe candidate for translation to human clinical trials, serving as a bridge to true NOTES.

Acknowledgments The authors would like to acknowledge the EURO-NOTES foundation for supporting this study. Secondly, authors would like to thank Goos M. Huijzer (biotechnician), Agaath A. Hanrath-den Hollander (endoscopy nurse), Theo G. Pordon (endoscopy nurse), and Prof. Dr. Mark van de Vijver (pathologist) for their assistance. Finally, authors would like to acknowledge Olympus Corporation, Storz Endoskope and Ovesco Endoscopy for supplying laparoscopic and endoscopic hardware and accessories.

Disclosures Rogier P. Voermans, Mark I. van Berge Henegouwen, Willem A. Bemelman, and Paul Fockens have no conflicts of interest or financial ties to disclose.

Open Access This article is distributed under the terms of the Creative Commons Attribution Noncommercial License which permits any noncommercial use, distribution, and reproduction in any medium, provided the original author(s) and source are credited.

\section{References}

1. Astudillo JA, Sporn E, Bachman S, Miedema B, Thaler K (2009) Transgastric cholecystectomy using a prototype endoscope with 2 deflecting working channels (with video). Gastrointest Endosc 69(2):297-302

2. Pai RD, Fong DG, Bundga ME, Odze RD, Rattner DW, Thompson CC (2006) Transcolonic endoscopic cholecystectomy: a NOTES survival study in a porcine model (with video). Gastrointest Endosc 64(3):428-434

3. Park PO, Bergstrom M, Ikeda K, Fritscher-Ravens A, Swain P (2005) Experimental studies of transgastric gallbladder surgery: cholecystectomy and cholecystogastric anastomosis (videos). Gastrointest Endosc 61(4):601-606

4. Perretta S, Dallemagne B, Coumaros D, Marescaux J (2008) Natural orifice transluminal endoscopic surgery: transgastric cholecystectomy in a survival porcine model. Surg Endosc 22(4):1126-1130

5. Rolanda C, Lima E, Pego JM, Henriques-Coelho T, Silva D, Moreira I, Macedo G, Carvalho JL, Correia-Pinto J (2007) Thirdgeneration cholecystectomy by natural orifices: transgastric and transvesical combined approach (with video). Gastrointest Endosc 65(1):111-117

6. Stark M, Benhidjeb T (2007) Transcolonic endoscopic cholecystectomy: a NOTES survival study in a porcine model. Gastrointest Endosc 66(1):208-209 
7. Sumiyama K, Gostout CJ, Rajan E, Bakken TA, Knipschield MA, Chung S, Cotton PB, Hawes RH, Kalloo AN, Kantsevoy SV, Pasricha PJ (2007) Transgastric cholecystectomy: transgastric accessibility to the gallbladder improved with the SEMF method and a novel multibending therapeutic endoscope. Gastrointest Endosc 65(7):1028-1034

8. Auyang ED, Hungness ES, Vaziri K, Martin JA, Soper NJ (2009) Human NOTES cholecystectomy: transgastric hybrid technique. J Gastrointest Surg 13(6):1149-1150

9. Bessler M, Stevens PD, Milone L, Parikh M, Fowler D (2007) Transvaginal laparoscopically assisted endoscopic cholecystectomy: a hybrid approach to natural orifice surgery. Gastrointest Endosc 66(6): 1243-1245

10. Marescaux J, Dallemagne B, Perretta S, Wattiez A, Mutter D, Coumaros D (2007) Surgery without scars: report of transluminal cholecystectomy in a human being. Arch Surg 142(9):823-826

11. Ramos AC, Murakami A, Galvao NetoM, Galvao MS, Silva AC, Canseco EG, Moyses Y (2008) NOTES transvaginal videoassisted cholecystectomy: first series. Endoscopy 40(7):572-575

12. Zornig C, Mofid H, Emmermann A, Alm M, von Waldenfels HA, Felixmuller C (2008) Scarless cholecystectomy with combined transvaginal and transumbilical approach in a series of 20 patients. Surg Endosc 22(6):1427-1429

13. Zorron R, Filgueiras M, Maggioni LC, Pombo L, Lopes Carvalho G, Lacerda Oliveira A (2007) NOTES. Transvaginal cholecystectomy: report of the first case. Surg Innov 14(4):279-283

14. Abramov Y, Gandhi S, Botros SM, Goldberg RP, Sherman W, Rurak M, Sand PK (2005) Do alterations in vaginal dimensions after reconstructive pelvic surgeries affect the risk for dyspareunia? Am J Obstet Gynecol 192(5):1573-1577

15. Francis W, Jefffcoate TN (1961) Dyspareunia following vaginal operations. J Obstet Gynaecol Br Commonw 68:1-10

16. Helstrom L, Nilsson B (2005) Impact of vaginal surgery on sexuality and quality of life in women with urinary incontinence or genital descensus. Acta Obstet Gynecol Scand 84(1):79-84

17. Ikeda K, Fritscher-Ravens A, Mosse CA, Mills T, Tajiri H, Swain CP (2005) Endoscopic full-thickness resection with sutured closure in a porcine model. Gastrointest Endosc 62(1):122-129

18. Kalloo AN, Singh VK, Jagannath SB, Niiyama H, Hill SL, Vaughn CA, Magee CA, Kantsevoy SV (2004) Flexible transgastric peritoneoscopy: a novel approach to diagnostic and therapeutic interventions in the peritoneal cavity. Gastrointest Endosc 60(1):114-117

19. Kratt T, Kuper M, Traub F, Ho CN, Schurr MO, Konigsrainer A, Granderath FA, Kirschniak A (2008) Feasibility study for secure closure of natural orifice transluminal endoscopic surgery gastrotomies by using over-the-scope clips. Gastrointest Endosc 68(5):993-996

20. Magno P, Giday SA, Dray X, Chung SS, Cotton PB, Gostout CJ, Hawes RH, Kalloo AN, Pasricha PJ, White JJ, Assumpcao L, Marohn MR, Gabrielson KL, Kantsevoy SV (2007) A new stapler-based full-thickness transgastric access closure: results from an animal pilot trial. Endoscopy 39(10):876-880

21. Pham BV, Raju GS, Ahmed I, Brining D, Chung S, Cotton P, Gostout CJ, Hawes RH, Kalloo AN, Kantsevoy SV, Pasricha PJ (2006) Immediate endoscopic closure of colon perforation by using a prototype endoscopic suturing device: feasibility and outcome in a porcine model (with video). Gastrointest Endosc 64(1):113-119

22. Ryou M, Fong DG, Pai RD, Rattner DW, Thompson CC (2008) Transluminal closure for NOTES: an ex vivo study comparing leak pressures of various gastrotomy and colotomy closure modalities. Endoscopy 40(5):432-436

23. Voermans RP, Worm AM, van Berge Henegouwen MI, Breedveld P, Bemelman WA, Fockens P (2008) In vitro comparison and evaluation of seven gastric closure modalities for natural orifice transluminal endoscopic surgery (NOTES). Endoscopy 40(7):595-601

24. von Renteln D, Eickhoff A, Kaehler G, Riecken B, Caca K (2009) Endoscopic closure of the natural orifice transluminal endoscopic surgery (NOTES) access site to the peritoneal cavity by means of transmural resorbable sutures: an animal survival study. Endoscopy 41(2):154-159

25. Voermans RP, van Berge Henegouwen MI, Bemelman WA, Fockens P (2009) Novel over-the-scope-clip system for gastrotomy closure in natural orifice transluminal endoscopic surgery (NOTES): an ex vivo comparison study. Endoscopy 41(12): 1052-1055

26. MacFadyen BV Jr, Vecchio R, Ricardo AE, Mathis CR (1998) Bile duct injury after laparoscopic cholecystectomy. The United States experience. Surg Endosc 12(4):315-321

27. Strasberg SM, Hertl M, Soper NJ (1995) An analysis of the problem of biliary injury during laparoscopic cholecystectomy. J Am Coll Surg 180(1):101-125

28. Voermans RP, van Berge Henegouwen MI, Bemelman WA, Fockens P (2009) Feasibility of transgastric and transcolonic natural orifice transluminal endoscopic surgery peritoneoscopy combined with intraperitoneal EUS. Gastrointest Endosc 69(7):e61-e67

29. de Reuver PR, Sprangers MA, Gouma DJ (2007) Quality of life in bile duct injury patients. Ann Surg 246(1):161-163

30. Chiu PW, Lau JY, Ng EK, Lam CC, Hui M, To KF, Sung JJ, Chung SS (2008) Closure of a gastrotomy after transgastric tubal ligation by using the Eagle Claw VII: a survival experiment in a porcine model (with video). Gastrointest Endosc 68(3):554-559

31. Dray X, Gabrielson KL, Buscaglia JM, Shin EJ, Giday SA, Surti VC, Assumpcao L, Marohn MR, Magno P, Pipitone LJ, Redding SK, Kalloo AN, Kantsevoy SV (2008) Air and fluid leak tests after NOTES procedures: a pilot study in a live porcine model (with videos). Gastrointest Endosc 68(3):513-519

32. McGee MF, Marks JM, Onders RP, Chak A, Jin J, Williams CP, Schomisch SJ, Ponsky JL (2008) Complete endoscopic closure of gastrotomy after natural orifice translumenal endoscopic surgery using the NDO Plicator. Surg Endosc 22(1):214-220

33. Sumiyama K, Gostout CJ, Rajan E, Bakken TA, Deters JL, Knipschield MA (2007) Endoscopic full-thickness closure of large gastric perforations by use of tissue anchors. Gastrointest Endosc 65(1):134-139

34. Rolanda C, Lima E, Silva D, Moreira I, Pego JM, Macedo G, Correia-Pinto J (2009) In vivo assessment of gastrotomy closure with over-the-scope clips in an experimental model for varicocelectomy (with video). Gastrointest Endosc 70(6):1137-1145

35. Park PO, Rothstein RI, Vassiliou MC, Stefanchik D, Vakharia OJ, Bally KR, Swain P (2009) A randomized study comparing hemostasis of laparoscopic clips delivered via flexible endoscopy versus conventional endoscopic clips on porcine mesenteric vessels. Gastrointest Endosc 69(5):AB163

36. Thele F, Zygmunt M, Glitsch A, Heidecke CD, Schreiber A (2008) How do gynecologists feel about transvaginal NOTES surgery? Endoscopy 40(7):576-580

37. Voermans RP, Sheppard B, van Berge Henegouwen MI, Fockens P, Faigel DO (2009) Comparison of transgastric NOTES and laparoscopic peritoneoscopy for detection of peritoneal metastases. Ann Surg 250(2):255-259

38. Larsen JF, Ejstrud P, Svendsen F, Pedersen V, Redke F (2002) Systemic response in patients undergoing laparoscopic cholecystectomy using gasless or carbon dioxide pneumoperitoneum: a randomized study. J Gastrointest Surg 6(4):582-586

39. Larsen JF, Svendsen FM, Pedersen V (2004) Randomized clinical trial of the effect of pneumoperitoneum on cardiac function and haemodynamics during laparoscopic cholecystectomy. Br J Surg 91(7):848-854 
40. Bowrey DJ, Blom D, Crookes PF, Bremner CG, Johansson JL, Lord RV, Hagen JA, DeMeester SR, DeMeester TR, Peters JH (2001) Risk factors and the prevalence of trocar site herniation after laparoscopic fundoplication. Surg Endosc 15(7):663-666

41. Puzziferri N, ustrheim-Smith IT, Wolfe BM, Wilson SE, Nguyen NT (2006) Three-year follow-up of a prospective randomized trial comparing laparoscopic versus open gastric bypass. Ann Surg 243(2):181-188

42. Narula VK, Hazey JW, Renton DB, Reavis KM, Paul CM, Hinshaw KE, Needleman BJ, Mikami DJ, Ellison EC, Melvin
WS (2008) Transgastric instrumentation and bacterial contamination of the peritoneal cavity. Surg Endosc 22(3):605-611

43. Narula VK, Happel LC, Volt K, Bergman S, Roland JC, Dettorre R, Renton DB, Reavis KM, Needleman BJ, Mikami DJ, Ellison EC, Melvin WS, Hazey JW (2009) Transgastric endoscopic peritoneoscopy does not require decontamination of the stomach in humans. Surg Endosc 23(6):1331-1336 